\title{
ELECTRIC SHIP POWER SYSTEM - RESEARCH AT THE UNIVERSITY OF TEXAS AT AUSTIN
}

By:

R.E. Hebner

IEEE Electric Ship Technologies Symposium (ESTS 2005), Philadelphia, Pennsylvania, July 25-27, 2005

$P N-298$

Center for Electromechanics

The University of Texas at Austin

PRC, Mail Code R7000

Austin, TX 78712

(512) $471-4496$ 


\title{
Electric Ship Power System - Research at the University of Texas at Austin
}

\author{
Robert E. Hebner, Fellow, IEEE
}

\begin{abstract}
Recognizing the importance of electric ships and the myriad of technical challenges they present, the University of Texas at Austin, with seed funding from the Office of Naval Research, established a virtual electrical ship research and development center. The reason for the virtual center is that the complex challenges of the future require multidisciplinary solutions. The virtual center contains staff members from Electrical Engineering, Mechanical Engineering and two research centers who work collaboratively with a number of other universities and with industry. This program has two anticipated significant outcomes. At the system level, the first anticipated outcome is to develop a comprehensive set of modeling approaches that guide the evolution of electric ship power systems. The second outcome is an approach to the replacement of the hydraulic system on current ships with electrical actuators on future ships.
\end{abstract}

Index Terms-AC motors, actuators, control, gas turbines, generators, marine electrical equipment, power system control, power system modeling, power system protection, thermal variables, power quality.

\section{INTRODUCTION}

$\mathrm{T}^{\mathrm{h}}$ he future electric ship presents a complex challenge, particularly for high technology warships. On the component level, the economics of ships places a premium on making each component as small, light, and energy efficient as possible. On the system level, advances in computing and power electronics are providing an expanding set of options to make the power system more reliable and versatile. The electric ship presents an opportunity and a challenge for shipbuilders. An important attribute of the opportunity the allelectric ship provides is that the rapid expansion of electrical and electronic capability provides a daunting array of options for ship designers and builders. An important challenge, however, is to select among these options to maximize performance and reliability simultaneously.

Recognizing the importance of electric ships and the myriad of technical challenges they present, the University of Texas at Austin, with seed funding from the Office of Naval Research, established a virtual electrical ship research and development center. The the complex challenges and multidisciplinary analysis commensurate with this problem

Primary funding for this work has been received from the Office of Naval Research as part of the Electric Ship Research and Development Consortium.

R. E. Hebner is with the Center for Electromechanics at the University of Texas at Austin, Austin, TX 78712 USA (e-mail: r.hebner@mail.utexas.edu). motivated the establishment of the center. The key organizational participants within the university are:

- Mechanical Engineering - Provides expertise in gas turbines, robotics, and mechanical system modeling and simulation.

- Electrical and Computer Engineering - Provides expertise in power system modeling and simulation, power quality, and signal analysis as applied to power systems.

- $\quad$ Applied Research Laboratories - Provides experience in transitioning advanced technology to the Navy, in information technology, and in control of complex systems.

- Center for Electromechanics - Provides expertise in the design, fabrication, and testing of advanced motors and generators, and modeling and simulation of the performance of novel systems, dielectrics, and magnetic materials.

While the internal cooperation is necessary, it is not sufficient. The UT program also benefits from interaction with other university researchers. Some of the most significant include:

- University of South Carolina - Advanced modeling and simulation.

- Florida State University - Modeling and testing of advanced components.

- Mississippi State University - Power system performance.

- Massachusetts Institute of Technology - Ship design and system modeling.

- Purdue - Power system dynamics.

- Naval Postgraduate School - Modeling of ship power systems.

In addition to the university collaborations, the UT research staff members are also addressing technologies for future electric ships in cooperation with industrial partners. These include Northrop Grumman, SAIC, General Atomics, DRS Technologies, Rockwell International, Curtis-Wright, Kato Engineering, Lockheed Martin, American Superconductor, and Timken.

\section{CURRENT Program}

The UT program is summarized in Figure 1. 


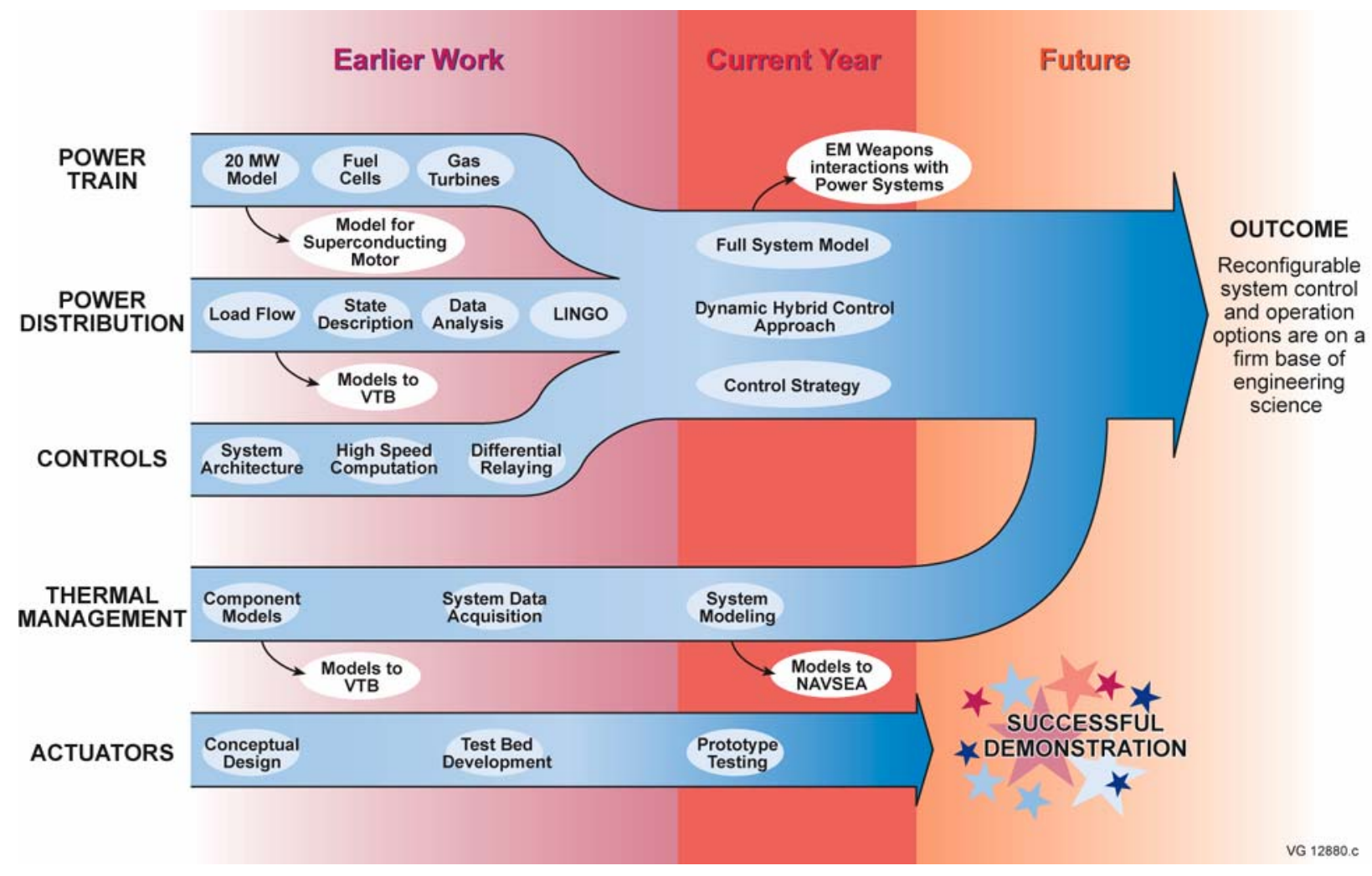

Fig. 1. The University of Texas maintains a coordinated program of research and development focused on improving the performance of future electric ships.

This program has two significant outcomes. At the system level, the objective is to develop a comprehensive set of modeling approaches that guide the evolution of electric ship power systems. These tools will facilitate evaluations of technology options prior to hardware fabrication, stimulate the reliable introduction of new technology into ship power systems, and provide for the future capability to reconfigure the ship's power system in times short compared to one cycle to maximize reliability and minimize collateral damage during component failure.

The second anticipated outcome is an approach to replace the hydraulic system on current ships with electrical actuators on future ships. The program has developed a proposed family of actuators that is currently being tested [1].

The University of Texas program is being conducted as five related programs: Power Train; Power Distribution; Controls; Thermal Management; and Actuators. Some of the activities and accomplishments in each of these areas are described below.

\section{A. Power Train}

The first phase of the work was to develop models [2] of the components in a representative power train. Figure 2 summarizes the power train options and the selection of a representative system that was made by UT. The detailed parameter choices and calculated component weights are shown in Table I. One obvious approach to establishing a baseline would have been to select a system that is already in service. A weakness of that approach is that any system in service lags the state-of-the-art by many years. A second, and potentially problematic constraint against using an actual system as a baseline, is there would likely be a continuing issue with proprietary information.

To overcome these problems, this work describes a preliminary design effort that focuses on a reasonable choice of a system using advanced, but currently available, technology. This permits the baseline to be current state-ofthe-art technology even though the technology has not yet been tested in service. Such an approach should provide the basis for meaningful advances. Since most of the components are designed for this application by university staff, criticisms of, and improvements to, the designs do not infringe on any proprietary systems.

Table I. Specifications of the key parameters of the UT model power train.

\begin{tabular}{|l|l|l|l|}
\hline \multicolumn{1}{|c|}{ Gas turbine } & \multicolumn{1}{|c|}{ Radial Flux PM } & \multicolumn{1}{c|}{ PWM converter } & \multicolumn{1}{c|}{ Radial Flux PM } \\
\hline - GE LM2500 Gas turbine & $-21 \mathrm{MW}$ (same as IPS) & $-20.5 \mathrm{MVA}$ (IPS=22 MVA) & $-19 \mathrm{MW}$ (same as IPS) \\
-20 tonnes (same as IPS) & $-3600 \mathrm{RPM}$ & - Input: $4160 \mathrm{Vac} 3 \mathrm{ph} 60 \mathrm{~Hz}$ & $-0-150 \mathrm{RPM}$ \\
& -4160 Volts AC & - Output: $0-3700 \mathrm{~V}, 0-15 \mathrm{~Hz}$ & -12 poles -15 phases \\
& -3 phases $(60 \mathrm{~Hz})$ & - IGBTs $(1600 \mathrm{~V}, 1200 \mathrm{~A})$ & - - Water-cooled coils \\
& -16 pole & $-2 \mathrm{KHz}$ switching frequency & $-35 \mathrm{Gs}$ shock load \\
& - Water-cooled coils & - Sea water cooled & -95 tonnes (IPS=117 tonnes) \\
& - - iir-cooled rotor & -16 tonnes (IPS= 17 tonnes) & \\
& -35 Gs shock load & & \\
& -12.5 tonnes (IPS=20 tonnes) & & \\
\hline
\end{tabular}

The major findings of that work were: (1) efficiency improvement offers the highest mass and volume pay-off, (2) the propulsion motor is the next best opportunity for size and weight reduction, and (3) the generator is the smallest single component in the power train, so an improvement in its size or weight has little effect on the total weight and volume of the power train. A smaller generator, however, may provide more flexible placement and, thus, improve ship architecture. 


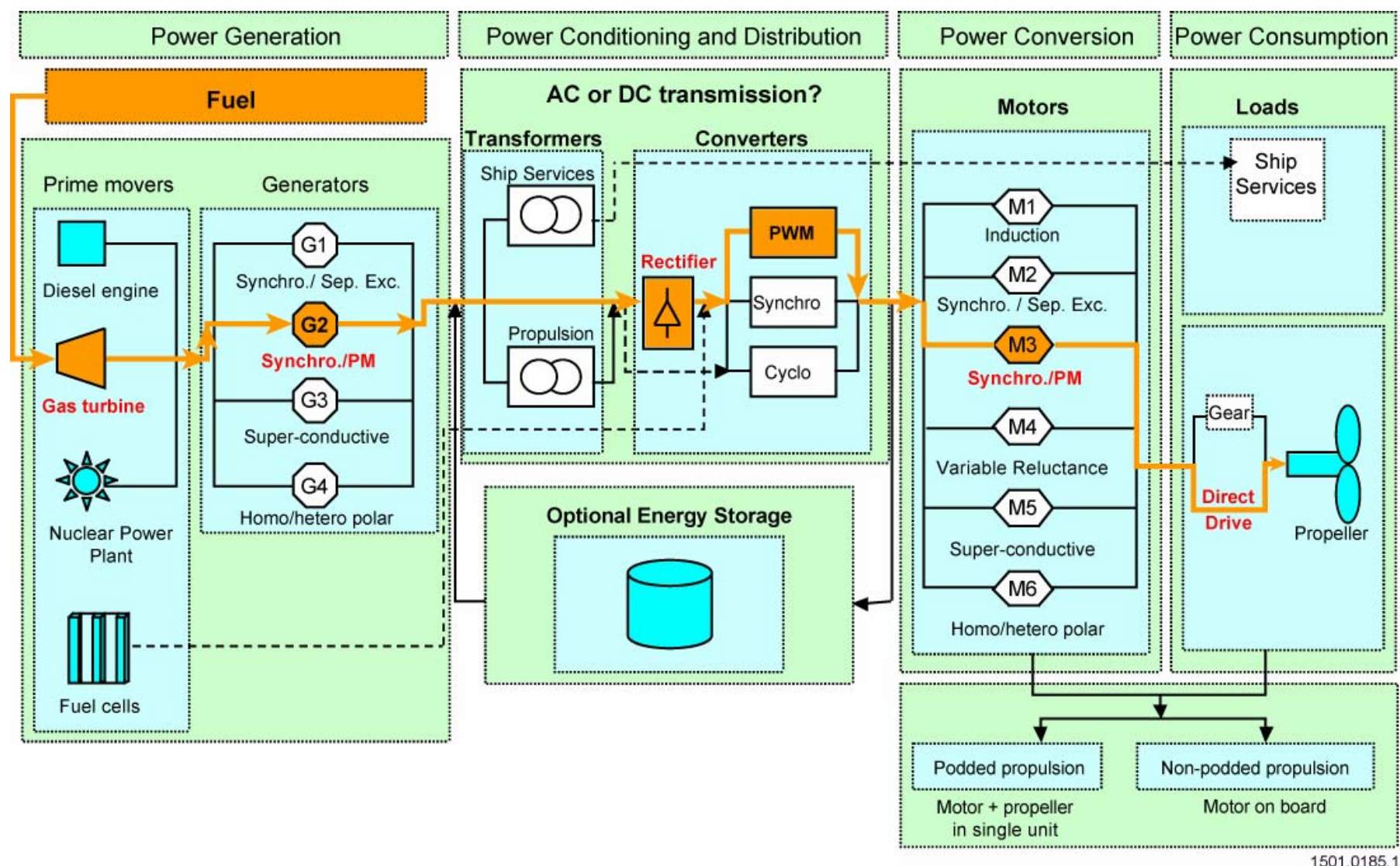

Fig. 2. Potential options for the power train of an electric ship. The heavy line through the figure highlights the selections that were made to describe a representative system.

This work has led to collaborations with machine developers to incorporate the technology developed into improved versions of their products. In addition, it has provided detailed knowledge needed for improved power system modeling [3]. This system modeling capability has already shown its value in assessing the impact of high power pulsed loads on power system behavior [4].

The current focus is on evaluating various modeling

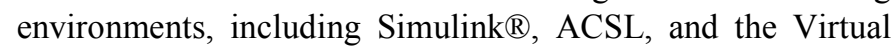
Test Bed at the University of South Carolina, to assess their strengths and weaknesses in simulating advanced ship power systems. In addition, work is going forward in key component areas, particularly in the area of gas turbines and electrical generators. This combination should provide an interesting trade opportunity for ship designers when the needed engineering data are available. The primary reason they make an interesting combination is that if turbine generators could be made smaller and lighter they could be placed higher in a ship. The higher they are in the ship, the less volume is needed for intake and exhaust ducting for the turbine. The placement will, however, impose power cabling requirements. Fundamental limits to joint turbine-alternator size are being investigated. This is an extension of the earlier work that showed the power rating and use patterns of the gas turbines had significant influence on fuel efficiency [4].

Finally, the accuracy of modeling and simulation is limited by the accuracy of material parameters at the conditions of use in an electric ship power system. Because this will be a very power dense system, the components are going to operate at unprecedented levels of combined electromagnetic, mechanical, and thermal stresses. The program is working to identify fundamental shortfalls in knowledge about available and emerging materials $[5,6]$. It is anticipated that this data will help materials scientists and engineers focus their work on areas needed by electric ship designers.

\section{B. Power System}

The power distribution system of future electric ships will likely be very different from land-based power systems. The key technical differences are the low impedance of the system due to its small size and the fact that individual loads can consume significant fractions of the total available power. The other difference is that there is a greater premium on rapid reconfiguration of a partially disabled system to support maximum capability at all times.

The UT work began with load flow and stability analyses of model systems to understand system parameters and power quality issues. More recent work has focused on validation of ship power system models using a land-based three-generator system and the use of power system signals to locate faults. In particular, software has been developed to carry out timefrequency analysis of transient events in power systems [7][9]. This application of advanced signal processing techniques is one of the advances needed in order to extract reliable information from power system transients to guide control decisions [10]. In addition, to ensure a robust power system it is increasingly important to improve the design and use of the sensor system that provides the data needed for control [11]. Other work includes determination of the magnitude and 
direction of real and reactive power flow associated with interharmonics [12]. Interharmonics are an important issue in electric ships since they are generated by the nonlinear frequency converters associated with variable speed drives and are capable of exciting undesired mechanical or electrical resonances. Lastly, higher-order coherence spectra have been utilized to provide nonlinear signature information associated with the degradation of rotating machines [13].

Initial work in reconfiguration built on early work in static reconfiguration by Butler et al. [14]. The initial accomplishments were to extend that path finding analysis of a dc radial system with current loads to include a dc network with current loads, a dc network with power loads, ac networks with real and reactive loads, and a dc approximation to the ac system. The more recent emphasis has been on the dynamics of reconfiguration $[15,16]$. Theoretically, it has been known that the order of switching from one system state to another can affect the instability of the system. Fundamental insights into this phenomenon have led to generalized methods to eliminate potential instabilities. Simulations have shown that these theoretical instabilities will occur in systems as small and as tightly coupled as those found on electric ships.

In addition, efforts have been made to ensure power quality is maintained in the electric ship system to provide a system that is compatible with electronic and other sensitive loads $[17,18]$

\section{Controls}

The controls research is focused on a control scheme that permits both continuous optimization of the power system configuration and rapid identification and correction of failed components. It is an attempt to combine the traditional disciplines of power system protection and power system control into a single system. Once the successful merger has been achieved, the process will be accelerated to determine how quickly reliable control decisions can be made.

The initial effort was analogous to conventional differential relaying schemes [19]. Traditional analog differential relays have circuits that allowed currents into and out of any zone of a power system to cancel each other in normal operation. Any fault that upset this balance causes the differential relay to trip, isolating the monitored zone. Implementing this digitally, the voltages and currents are measured at each node of a complex circuit. If the voltage and current are sampled three times in about a quarter of a cycle, a reliable identification of a fault can be made, even in the presence of electrical noise.

As the fault is being isolated, the system calculates the optimum target system state. Various approaches to optimize the system are being evaluated, including branch and bound, simulated annealing, and the use of genetic algorithms. All of these approaches work, but the genetic algorithm may be the most easily parallelizable. The challenge is to determine the approach that produces the most rapid identification of a locally optimal solution [20]. Acceptable solutions can be computed in less than $1 \%$ of the time required for a global solution

\section{Thermal Management}

An electric ship generating 80-100 MW of nearly continuous electrical output power will quite likely convert more than $25 \%$ of that power into "waste" heat. The thermal management project is addressing this heat load at the system level to determine options for removing heat that cannot be reused and to find ways to reuse heat to increase the total system efficiency. This effort has developed an architectural representation of the thermal loads on a DDG-51 class ship [21]. In addition, it is focusing on the characterization of key future components of electric ships such as fuel cells and electromagnetic guns. As indicated in figure 1, the expectation in this work is to merge the thermal modeling capability with the electrical modeling capability, producing a simulation approach that permits ship designers to address thermal management earlier in the design process to produce more efficient, less costly ship power systems.

\section{E. Actuators}

The transition to an all electric ship brings with it the possibility of converting the hydraulic system to an electric system. To help achieve this promise, a family of electric actuators with high performance and a common architecture has been developed. The common architecture is critical to reduce training and maintenance costs. Moreover, the actuators are fitted with sensors that permit condition-based maintenance, further reducing the maintenance costs. In cooperation with industrial partners, a prototype actuator of this type has been fabricated and is undergoing testing [1].

\section{SUMMARY}

The multidisciplinary research team at the University of Texas at Austin is working with the government, companies, and other academic institutions to produce technology needed for future generations of electric ships. Through this research, the university is also educating students in the important attributes of ship technology. Both the technology and the educated staff members are critical to a competitive domestic presence in this important emerging technology.

\section{ACKNOWLEDGMENT}

The author gratefully acknowledges the contributions of the students and staff members from the Electrical and Computer Engineering Department, the Mechanical Engineering Department, the Applied Research Laboratories, and the Center for Electromechanics at the University of Texas at Austin.

\section{REFERENCES}

[1] D. Tesar, "Electro-mechanical actuators for the navy's ships," IEEE Electric Ship Technology Symposium, July 2005.

[2] J. Beno, J. Zierer, A. Ouroua, E. Schroeder, M. Flynn, D. Weeks, M. Pichot, D. Bogard, D. Robertson, K. Davey, and R. Hebner, "Design and analysis of a 20 MW propulsion power train," 7th Intl. Naval Engineering Conf. and Exhibition (INEC), Amsterdam, The Netherlands, March 16-18, 2004.

[3] A. Ouroua, L. Domaschk, J. H. Beno, "Electric ship power system integration analyses through modeling and simulation," IEEE Electric Ship Technology Symposium, July 2005. 
[4] R. Hebner, J. Pappas, J. Kitzmiller, K. Davey, J. Herbst, A. Ouroua, J. Beno, "An electromagnetic gun as a component of an electric ship power system," High-Power Weapons System for an Electric Ship Symposium 2004," Baltimore, MD, December 2004.

[5] A. Wilder, "Materials for advanced electrical machines: an overview," IEEE Electric Ship Technology Symposium, July 2005.

[6] A. Wilder, "Characterization of power losses in soft magnetic materials," IEEE Electric Ship Technology Symposium, July 2005.

[7] J. Billo, J. Carroll, J. Shin, A. Arapostathis, W. M. Grady, and E. J. Powers, "Research progress at the University of Texas: reconfiguration, cross time-frequency analysis and harmonic studies," IASME Transactions, vol. 1, pp 199-204, April 2004.

[8] Y.-J. Shin, E. J. Powers, W. M. Grady, and A. Arapostathis, "Power quality indices for transient disturbances," to appear in IEEE Transactions on Power Delivery.

[9] Y.-J. Shin, A. Monti, F. Ponci, A. Arapostathis, W. M. Grady, E. J. Powers, and R. Dougal, "Virtual power quality analysis for ship power system design," Proceedings of the IEEE 2004 Instrumentation and Measurement Technology Conference (IMTC 2004), Como, Italy, May $18-20,2004$

[10] W. M. Grady, T. Kim, E. J. Powers, A. Arapostathis "Real and reactive power analysis for interharmonics," IEEE Electric Ship Technology Symposium, July 2005.

[11] W. Wu and A. Arapostathis, "Optimal control of stochastic systems with costly observations $-\mathrm{x}$ the general Markovian model and the LQG problem," 2005 American Control Conference (ACC), Portland, Oregon, June 8-10, 2005.

[12] T. Kim, E. J. Powers, W. M. Grady, and A. Arapostathis "Real and reactive power analysis for interharmonics," IEEE Electric Ship Technology Symposium, July 2005.

[13] B. Jang, C. Shin, E. J. Powers, and W. M. Grady, "Machine fault detection using bicoherence spectra," Proceedings of the IEEE 2004 Instrumentation and Measurement Technology Conference (IMTC 2004), Como, Italy, May 18-20, 2004.

[14] K. Butler, N. Sarma, and V. Prasad, "A new method of network reconfiguration for service restoration in shipboard power systems," 1999 IEEE Transmission and Distribution Conference, Vol. 2, pp. 658-662, April 1999.

[15] A. Arapostathis, W. M. Grady, and E. J. Powers, "A hybrid systems approach to dynamic reconfiguration," IASME Transactions, vol. 1, pp 294-299 April 2004.

[16] A. Arapostathis, "A hybrid systems approach for power systems reconfiguration and numerical studies using Dymola," IEEE Electric Ship Technology Symposium, July 2005.

[17] W. M. Grady, M. Rylander, A. Arapostathis, E. J. Powers "A voltagesag procedure for determining transient stability models of conventional linear loads," IEEE Electric Ship Technology Symposium, July 2005.

[18] W. M. Grady, G. Tilte, E. J. Powers, A. Arapostathis "Investigation of harmonic source locations," IEEE Electric Ship Technology Symposium, July 2005.

[19] K. Davey and R. Hebner, "Reconfiguration of shipboard power systems," IASME Transactions, vol. 1, pp 241-246, April 2004.

[20] K. Davey and R. Hebner, "Reconfiguration: a tool for designing new ships," IEEE Electric Ship Technology Symposium, July 2005.

[21] S. Haag and T. Kiehne, "Simulation of DDG-51 Thermal management systems," Systems for Electric Ship, High-Power Weapons System for an Electric Ship Symposium 2004, Baltimore, MD, December 2004.

\section{Biography}

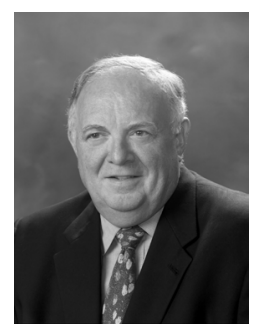

Robert E. Hebner, Ph.D., is Director of the Center for Electromechanics at the University of Texas at Austin. The Center develops technology, primarily novel motors, generators, and suspension components, and teams with companies to get the technology into the market.

Previously, Dr. Hebner was the acting Director of the U.S. National Institute of Standards and Technology (NIST). In addition, he has directed NIST's Electronic and Electrical Engineering Laboratory, a laboratory with a staff of more than 250 . He also worked at the Defense Advanced Research Projects Agency where he developed programs to improve semiconductor manufacturing.
Throughout his career, Dr. Hebner has been active in having authored or coauthored more than one hundred technical papers and reports. He has extensive experience in international technology programs. This work included the modernization of the measurement systems needed to support global trade and the assessment of the effectiveness of government technology programs in stimulating domestic economies. 